\title{
Metafora Kastil JePang Dengan Sifat Menumpuk Ala Lego Pada Perancangan Pusat Komunitas JePang Di Solo Raya, JaWa Tengah
}

\author{
M. Dirham Okta Raizal ${ }^{1 *}$, Hardiyati ${ }^{2}$, Maya Andria Nirawati ${ }^{3}$ \\ Program Studi Arsitektur, Fakultas Teknik, Universitas Sebelas Maret ${ }^{1}$ \\ E-mail: dirham95@yahoo.com* \\ Program Studi Arsitektur, Fakultas Teknik, Universitas Sebelas Maret ${ }^{2}$ \\ Program Studi Arsitektur, Fakultas Teknik, Universitas Sebelas Maret ${ }^{3}$
}

\begin{abstract}
This journal was done in the interest of architectural studies. The goal of the research was to build a Japanese Community Center in Solo. The study began from a certain phenomenon. Ever since the signing of Peace Treaty between Indonesia and Japan, both country had immersed themselves in various cultural exchanges. This leads to the increase of Japanese culture lovers in Indonesia almost every year. To anticipate and control this phenomenon, a place that can hold and regulate the speed and effects of it is needed. The Japan Community Centre will be a place for Japanese Communities's activities, a medium for learning Japanese culture, and the new spot of historical vacation for Solo City. Metaphorical Architecture was chosen as the design approach with consideration that through Metaphorical Architecture, the character and purpose of the building can be better presented for the public. The Metaphorical Architecture used was the mix of Abstract Metaphor (intangible) and Concrete Metaphor (tangible). The main problem of this designing process is what will be metaphored through this Japan Community Centre. The exploration starts from chosing the name for the building, which is Mugen Jou (Infinity Castle). The metaphorical charcteristics that will be used, based on the name chosen, are Grand, Firm, Massive, The feel of Japanese Castle, Uncountable visualization, and Stacked ala Lego.
\end{abstract}

Keywords: Metaphorical, Grand, Firm, Massive, Castle, Uncountable

\section{PENDAHULUAN}

\section{Latar Belakang}

Dunia saat ini ditopang oleh aktivitas dan hubungan antar negara - negara yang ada di dalamnya. Di era "Globalisasi" ini, suatu negara dapat berkembang atau terpuruk bergantung pada kemampuannya untuk beradaptasi. Dalam hal tersebut, Indonesia yang masih sebagai negara 'berkembang', perlu menjalin hubungan yang kuat dengan negara - negara lain yang lebih maju perkembangannya. Dalam hal ini salah satunya dengan Negara Jepang. Jepang. Meskipun bukan merupakan negara yang besar dan luas, Jepang merupakan salah satu pilar utama dunia yang memegang peranan penting pada kemajuan berbagai jenis aspek, di antaranya ekonomi dan IPTEK (Ilmu Pengetahuan dan Teknologi). Karena predikat tersebut, menjalin hubungan yang kuat dengan Jepang, tentu dapat membantu perkembangan negara karena pembelajaran yang diambil dari sumber yang terpercaya.

Hubungan bilateral antara Indonesia dengan Jepang dimulai sejak Penandatanganan Perjanjian Perdamaian yang dilakukan oleh Menteri Luar Negeri Indonesia Soebandrio, dan Menteri Luar Negeri Jepang Fujiyama Aichiro pada tanggal 20 Januari 1958 [http://www.kemlu.go.id/tokyo/id/Pages/Jepang.aspx]. Pada awal penandatanganan, hubungan ini hanya berfokus pada pengembangan sektor ekonomi, namun seiring waktu juga memperhatikan sektor pendidikan, perdagangan, bantuan, pertahanan, dan pertukaran elemen kebudayaan. Pertukaran elemen kebudayaan yang dimaksud tidak hanya soal kebudayaan tradisional yang dimiliki negara masing masing, namun juga mencakup hal - hal lain yang mencirikan negara tersebut.

Efek dari pertukaran elemen budaya yang paling marak saat ini di Indonesia adalah mulai banyak bermunculan acara atau festival - 
festival yang bertajuk budaya Jepang sebagai motifnya (matsurii atau festival) diadakan di Indonesia [http://www.kompasiana.com/fitriharyanti/jepang -agen-pop-culture-nya-asia_550e76e1a33311af2dba8106].

Sayangnya, acara - acara budaya yang diadakan dilakukan tanpa persiapan yang benar-benar matang sehingga tidak jarang justru mengundang pandangan negatif dari masyarakat umum. Ini turut menurunkan semangat mereka untuk lebih memahami kebudayaan asing yang menjadi motifnya. Persiapan yang dimaksud mencakup pemilihan lokasi, pemilihan tanggal pengadaan acara, sampai kontrol terhadap ruang lingkup acara terhadap lingkungan sekitar. Hal ini cukup terasa di Kota Solo yang juga sering digelar acara - acara serupa.

Efek lain dari pertukaran kebudayaan ini adalah lahirnya berbagai macam komunitas berbasis budaya Jepang di Indonesia [http://www.kompasiana.com/matapanda/budaya-populerjepang-yang-kian-marak_57a4a2922123bd9912f4ef0a].

Secara gamblang, komunitas - komunitas ini berdiri karena minat mereka terhadap berbagai aspek kebudayaan modern dari Jepang seperti anime, manga, dan cosplay. Meskipun ada juga yang mendalami budaya tradisional Jepang seperti AIKIKAI JOGJA, sebuah dojo (perguruan) untuk ilmu bela diri asal Jepang, Aikido.

Pada tahun 2012 lalu, Yoshinori Katori, duta besar Negara Jepang untuk RI, mendapat kesempatan berkunjung ke Kota Solo [http://www.edisicetak.joglosemar.co/berita/buktikan-sendirisolo-mirip-kota-nara-di-jepang-75633.html]. Didampingi oleh Sekretaris III Bagian Politik, Kaori Morohira, kunjungan tersebut berfokus kepada Bengawan Solo yang merupakan simbol atau ciri khas utama Kota Solo, melihat potensi investasi di kota ini, dan kesempatan bertukar pikiran dan pengalaman dengan masyarakat Jepang terutama mahasiswa(i) yang tengah tinggal atau menetap di Kota Solo. Pada kesempatan ini pula, Yoshinori mengatakan bahwa banyak warga negaranya yang memutuskan untuk datang dan menetap di Kota Solo untuk mempelajari budaya lokal lebih dalam. Menurut penuturan beliau, ada sekitar 20 lebih komunitas yang terbentuk dari warga negara Jepang di kota ini meskipun jumlah pastinya belum dapat disebutkan. Namun jumlah ini masih belum termasuk kepada komunitas - komunitas lainnya yang dibentuk oleh warga Indonesia di Kota Solo itu sendiri. Dilihat dari skala peminat atau anggotanya, komunitas Jepang di Solo dapat dibagi menjadi dua kategori:

- Komunitas umum yang menerima anggota dari berbagai golongan selama mereka memiliki kesamaan minat atau visi-misi dengan komunitas yang hendak dimasuki, dan

- Ekstrakurikuler yang hanya meliputi lingkup sekolah tempat ekstrakurikuler tersebut dimulai.

Berdasarkan hasil pengamatan terhadap beberapa komunitas Jepang di Solo, dapat disimpulkan bahwa kebanyakan komunitas komunitas ini bersifat terbuka, mengecualikan yang bertipe ekstrakurikuler yang dibatasi lingkup instansi. Komunitas - komunitas ini rata - rata tidak memiliki ruang sendiri untuk mengadakan acara kumpul - kumpul seperti itu, dan sering memanfaatkan fasilitas fasilitas umum yang tersedia. Dari fenomena ini dapat kita tarik kesimpulan bahwa kebutuhan akan ruang khusus bagi komunitas - komunitas ini bertemu dan berdiskusi atau lainnya sangat diperlukan.

Karena permasalahan tersebut, sudah saatnya Indonesia lebih memperhatikan dampak dari pertukaran budaya antara Jepang dan Indonesia, contohnya di Kota Solo yang memang sudah banyak digelar acara - acara bertajuk budaya Jepang dan lahirnya komunitas - komunitas Jepang. Pengawasan terhadap trend baru penyebaran budaya ini tentunya akan lebih mudah dan lebih positif bila kegiatannya terfokus di suatu titik. Selain dapat memperhalus interaksi degan masyarakat awam, juga mempermudah masyarakat awam yang memang memiliki keinginan untuk mempelajari kebudayaan Jepang yang telah marak di Indonesia. Untuk itu sebuah Pusat Komunitas yang akan mewadahi kegiatan kegiatan komunitas berbasis budaya Jepang dan juga pergelaran acara - acara bermotif budaya Jepang adalah jawaban yang cukup tepat.

\section{Arsitektur Metafora}

Arsitektur Metafora Mengekspresikan secara eksplisit dan implisit kandungan metafora (permisalan, perwujudan, atau penggambaran) dan metafisika (spiritual) ke dalam bangunan 
[Charles Jenck, 1984]. Atau dengan kata lain metafora adalah suatu bentuk penggambaran yang bersifat bebas karena dapat dipresentasikan dengan media dan visualisasi apa saja. Visualisasi ini akan mengundang persepsi yang berbeda - beda pada setiap pengamat. Aspek metafora ini juga menguji batasan imajinasi perancang sekaligus menggalinya lebih dalam.

Arsitektur Metafora secara umum terbagi menjadi 3:

- Metafora Konkrit

Menggambarkan bentuk-bentuk yang ada di dunia nyata dan dapat dilihat dengan jelas seperti mobil, burung, dsb.

- Metafora Abstrak

Menggambarkan hal-hal yang biasanya tidak dapat dilihat secara jelas bentuknya bentuknya seperti angin/udara dan air. Dapat juga menggambarkan transisi, ide, filosofi, dll

- Metafora Gabungan

Gabungan antar kedua jenis metafora sebelumnya dimana menggambarkan suatu hal secara konkrit dan abstrak sekaligus. Atau menggambarkan dua objek (konkrit dan abstrak) dalam satu objek rancangan.

\section{METODA PERANCANGAN}

Langkah - langkah metoda perancangan dilakukan dalam 3 tahap:

- Manajemen Data

Langkah ini terbagi menjadi Pengumpulan Data dan Pengolahan Data. Pengumpulan Data dilakukan melalui 4 jalur, yakni referensi secara online, literatur, wawancara, dan observasi. Data - data yang didapat kemudian dikumpulkan dan diolah kembali dengan mengambil hanya bagian bagian yang substantial atau penting dalam perancangan. Data-data statistic akan diolah menjadi diagram atau table yang lebih mudah dimengerti

- Pendekatan/Eksplorasi Konsep

Tahap perumusan untuk menentukan gambaran dasar Pusat Komunitas Jepang yang akan dirancang.

Eksplorasi desain Pusat Komunitas Jepang ini dimulai dari pengambilan nama kompleks bangunan. Nama yang digunakan untuk bangunan Pusat Komunitas ini adalah "Mugen Jou" (Kastil Tak Terhingga). "Mugen Jou" merupakan setting lokasi dalam salah satu cerita manga (komik Jepang) berupa sebuah kompleks bangunan high-rise terbengkalai namun dihuni oleh golongan masyarakat yang terasingkan (minoritas) di Shinjuku, Tokyo. Nama tersebut diambil karena adanya kesamaan antara golongan minoritas tersebut dengan kelompok penggemar budaya Jepang, yang bersifat minoritas, sebagai pengguna utama bangunan pusat komunitas ini nantinya. Individu minoritas yang mencari sesamanya dan lahirnya kumpulan atau komunitas yang mereka bentuk. Karena itu, nama bangunan "Mugen Jou" dipilih karena mewakili fenomena yang serupa yakni kelompok minoritas berusaha mencari tempat yang dapat mereka tempati atau gunakan. Arsitektur Metafora yang ditetapkan sebagai pendekatan desain akan menerjemahkan nama Mugen Jou (Kastil Tak Terhingga) ini ke dalam Pusat Komunitas Jepang ini.

Hasil eksplorasi menunjukan bahwa kompleks bangunan Pusat Komunitas Jepang akan menggunakan pendekatan Arsitektur Metafora Gabungan untuk menunjukan karateristik berikut:

- Megah

- Kokoh

- Masif

- Suasana kastil - kastil kuno Jepang (dapat berupa elemen - elemen bangunan, material, tata letak, dll)

- Dapat menciptakan ilusi bentuk yang "Tak Terhitung" dengan bantuan visualisasi konkrit dari penyusunan puzzle atau lego.

- Transformasi Desain

Tahap penerjemahan konsep bangunan yang sudah ada ke dalam bentuk 3 dimensi bangunan. 


\section{HASIL DAN PEMBAHASAN}

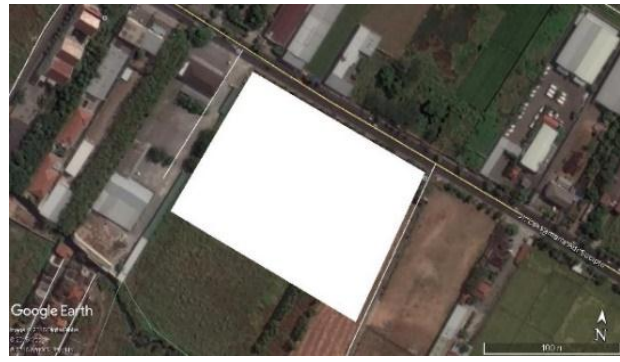

Gambar 1. Site Perancangan

(googlemaps.com)

Site perancangan terpilih berada di tepi jalan utama, Jl. Laksamana Adi Sucipto. Site ini dapat diakses dengan mudah menggunakan kendaraan umum, seperti BST. Di dekat site terdapat beberapa tempat makan, SPBU, ATM, Hotel Lor In, serta beberapa penginapan lainnya. Site berukuran kurang lebih 18.000 $\mathrm{m} 2$.

\section{Analisis Pencapaian}
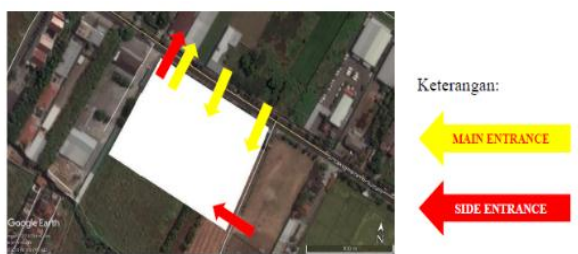

Gambar 2. Analisis Pencapaian

ME (Main Entrance) ditunjukan untuk jalur masuk pengunjung dan pihak pengelola. ME diletakan pada sisi jalan utama Jl. Laksamana Adi Sucipto. ME dibagi menjadi 2 untuk jalur masuk kendaraan dan jalur masuk pejalan kaki.

SE (Side Entrance) digunakan untuk jalur masuk kendaraan kargo. SE diletakan pada sisi kanan site yang merupakan jalur yang cukup sepi sehingga tidak menyebabkan kemacetan sirkulasi di dalam site.

\section{Analisis View}
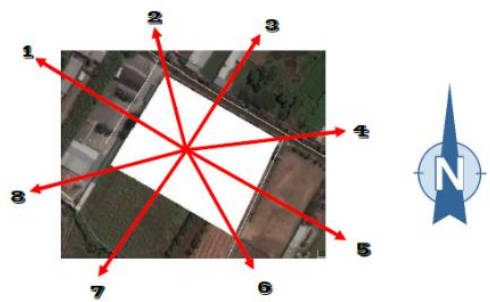

Gambar 3. Analisis View Ke Luar Site

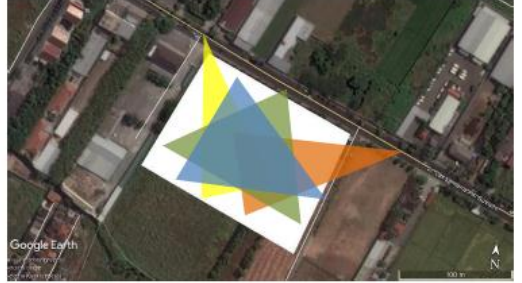

Gambar 4. Analisis View Ke Dalam Site

Orientasi bangunan diarahkan menuju arah 3 yang merupakan jalan utama dan arah 5 yang masih merupakan tanah kosong (menurut Gambar 3.). Peletakan bangunan diletakan di tengah site untuk penampilan terbaik gubahan massa pusat komunitas dari berbagai sisi.

\section{Analisis Kebisingan}

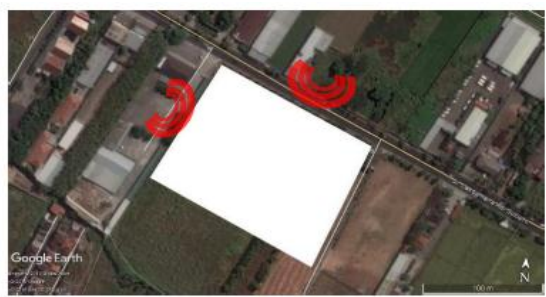

Gambar 5. Analisis Kebisingan

Potensi sumber kebisingan untuk site berjumlah dua sumber. Sumber kebisingan utama berasal dari sisi utara site yang merupakan jalan utama sehingga dilalui oleh berbagai macam kendaraan. Pada seberang jalan juga merupakan bangunan - bangunan dengan tingkat intensitas kepadatan manusia yang cukup tinggi. Sumber kebisingan kedua berasal dari Rumah Makan Taman Sari yang frekuensi kepadatannya cukup tinggi. Sementara itu, lansekap di sekitar site merupakan sawah kosong. Oleh karena itu, sangat sedikit sekali kemungkinannya untuk menimbulkan kebisingan, sehingga dapat diabaikan.

\section{Analisis Jalur Matahari}

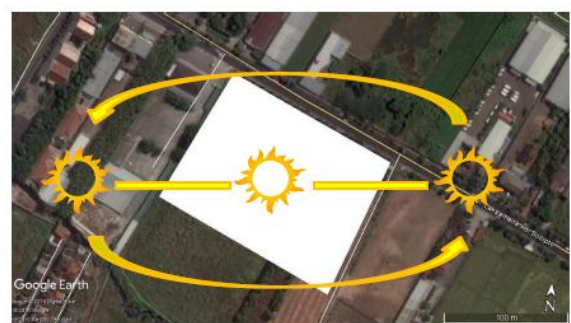

Gambar 6. Analisis Jalur Matahari

Lokasi site mendapatkan sinar matahari sejak matahari terbit namun baru terekspos secara penuh mulai pukul 08.00 WIB. Dikarenakan 
lansekap sekitar site yang kosong, site tidak mendapatkan banyak shading (lokasi sawah kosong tidak ada pohon liar). Shading baru didapat ketika menjelang sore dimana matahari menuju barat dan mulai terhalangi sedikit oleh bangunan Rumah Makan Taman Sari. Sepanjang pagi hari hingga sore hari, site mendapat sinar matahari secara menyeluruh.

\section{Analisis Lintas Angin}

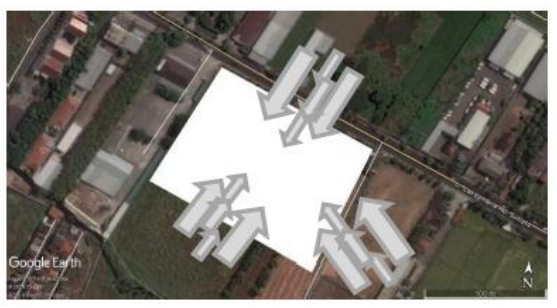

Gambar 7. Analisis Lintas Angin

Hembusan angin paling maksimal di lokasi ini adalah Angin Pasat Tenggara yang berhembus sepanjang tahun (dari arah Tenggara). Hembusan angin juga terasa berhembus dari sisi utara dan selatan site karena tidak terhalangi oleh bangunan tinggi. Hembusan berkurang menjelang siang (terutama saat musim kering) dan mulai bertambah kencang menjelang sore hari.

\section{Hasil Analisis Site}

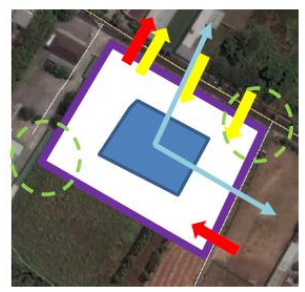

Gambar 8. Hasil Analisis Site

- Panah kuning merupakan Main Entrance yang digunakan oleh kendaraan dan pejalan kaki, sedangkan Side Entrance digunakan untuk aktivitas servis.

- Posisi bangunan diletakan kurang lebih di tengah site (kotak biru) dengan orientasi menuju jalan utama dan sisi Timur site (panah biru).

- Bingkai ungu merupakan barrier untuk menghalangi noise dengan konsentrasi vegetasi pada sisi site yang menjadi jalur matahari (lingkaran hijau).

- Dikarenakan sirkulasi angin yang masih bebas di dalam site, bukaan pada bangunan dapat diletakan pada sisi manapun.

\section{Analisis Peruangan}

Ruang - ruang di dalam pusat komunitas ini dapat dibagi menjadi 3 kelompok yaitu Penerima, Fasilitas, dan Pengelola.

- Kelompok ruang Penerima terdiri dari gerbang masuk, parkir kendaraan, drop off, dan lobby.

- Kelompok ruang Fasilitas terdiri dari masjid, taman atm, rumah teh, gallery, gift shop, studio tari dan karaoke, perpustakaan, taman jajan, communal space, ruang seminar/workshop, open plaza (yang dapat dimanfaatkan untuk outdoor stage), serta indoor stage.

- Kelompok ruang pengelola terdiri dari loading dock, gudang, pos keamanan, dan kantor pengelola,

Lebih lanjut, hubungan ruang ketiganya dapat dilihat pada diagram berikut:

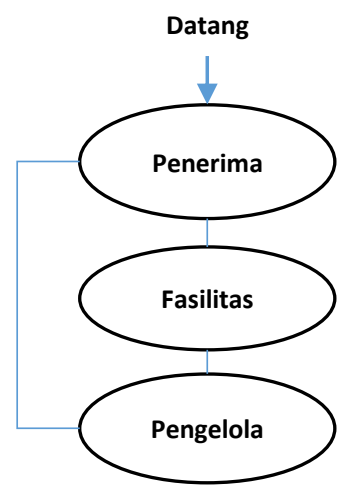

Grafik 1. Hubungan Ruang Dalam Pusat Komunitas

\section{Analisis Gubahan Massa Bangunan}

Seperti yang telah ditentukan sebelumnya, pusat komunitas akan mengusung karakteristik - karakteristik sebagai berikut:

- Megah

- Kokoh

- Masif

- Suasana kastil - kastil kuno Jepang

- Visualisasi bentuk yang "Tak Terhitung"

Dirangkum dari hasil pemaparan terhadap sifat - sifat yang diwakili berbagai bangun datar oleh Valerie Mace (Creative Director dari biro konsultan desain dan marketting UK, Panacentric), didapat hasil sebagai berikut: 
- Massa bangunan dan segala bentuk infrastruktur lainnya akan dibentuk menggunakan kombinasi bangun - bangun 3 dimensi kubus dan balok

- Aksen - aksen (bila ada) diberi dalam bentuk vertikal atau bersudut lancip dan segitiga sesuai kebutuhan

- Massa bangunan akan menonjolkan visualisasi bentuk yang "Tak Terhitung" menggunakan sifat menumpuk ala Lego

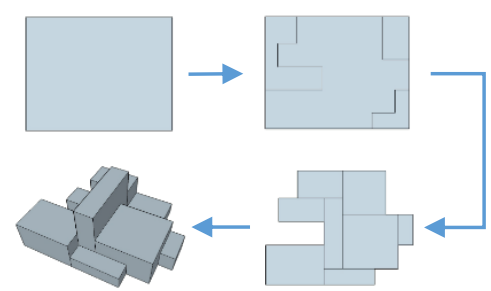

Grafik 2. Transformasi Desain Massa Bangunan

Transformasi desain berikut diaplikasikan pada semua bangunan kecuali Kantor Pengelola.

Kemudian, untuk penonjolan suasana kastil Jepang, akan dilakukan dengan menghadirkan beberapa elemen penting yang biasa terdapat di dalam kastil-kastil Jepang. Elemen-elemen yang dimaksud antara lain:

\section{- Bailey (Lingkar Kastil)}

Bailey merupakan sebutan untuk tata letak yang dipakai pada pembangunan kastil kastil Jepang. Kastil Jepang menggunakan Bailey untuk membagi wilayahnya menjadi lingkar-lingkar dengan jumlah tertentu. Minimum jumlah lingkar yang digunakan berjumlah 3. [http://www.jcastle.info/resources/view/ 8-Structures]

Pusat komunitas nantinya juga menggunakan Bailey dalam penataan dengan jumlah 3 lingkar.

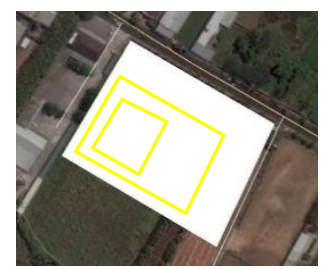

Gambar 9. Aplikasi Bailey pada Site

- Lingkar terluar Maru digunakan untuk fasilitas penerima seperti parkir dan jalur servis
- Lingkar tengah Maru akan digunakan untuk fasilitas - fasilitas

- Lingkar dalam Maru akan digunakan untuk Pantor Pengelola dan Hall

- Pembagian ini nantinya yang juga membantu membuat pola sirkulasi yang linear namun dengan tata letak bangunan yang memusat pada Kantor Pengelola dan Hall

- Tiap Maru akan mengalami peninggian tanah hingga $1 \mathrm{~m}$

- Bori (Parit Kastil)

Bori merupakan parit yang biasanya dibangun pada garis tepi terluar kompleks kastil. Bori dibangun sebagai lini pertahanan pertama kastil. [http://www.jcastle.info/resources/view/78-Structures]

Pusat komunitas juga menerapkan Bori pada tepi terluar site. Hanya saja, dikarenakan posisi site yang bersebelahan dengan bangunan dan kavling lainnya, Bori diterapkan pada tepi site yang bersebelahan dengan tepi jalan. Bori berupa parit basah yang dibentuk menjadi kolam hias.

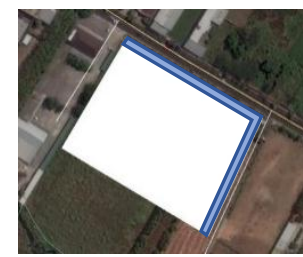

Gambar 10. Aplikasi Bori pada Site

\section{- Ishigaki (Tembok Batu)}

Ishigaki merupakan tembok batu yang menjadi penanda garis Bailey. Ishigaki biasanya dibangun agar tidak mudah dipanjat karena fungsinya sebagai pertahanan.

[http://www.jcastle.info/resources/view/78-Structures]

Aplikasi Ishigaki pada pusat komunitas hanya sebagai tembok pengeliling Bailey.

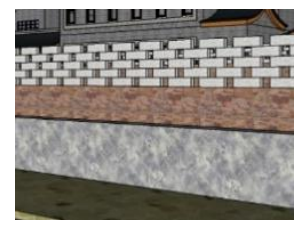

Gambar 11. Aplikasi Ishigaki pada Site

Bagian bawah yang merupakan permukaan batu akan dipotong menurut pola yang rapi dan teratur sehingga nilai estetikanya bertambah. Bagian dinding atasnya 
terbentuk dari balok - balok seragam yang disusun dengan jarak.

\section{- Tenshu (Kastil Utama)}

Tenshu merupakan bangunan yang benar benar merupakan kastil utama dalam suatu kompleks kastil. Disinilah penguasa kastil dan keluarganya tinggal. Tenshu dibentuk dengan berbagai gaya dan cara penyusunan, namun selalu berupa bangunan dengan lantai atas lebih kecil dibandingkan lantai bawahnya (layaknya pagoda). [http://www.jcastle.info/resources/view/78-Structures]

Aplikasi Tenshu pada pusat komunitas digunakan untuk bangunan Kantor Pengelola yang ,sama seperti Tenshu, memegang peranan penting dalam kompleks bangunan. Gaya Fukugoshiki digunakan dimana ada sebuah ruang yang menonjol sendiri pada lantai dasar bangunan.

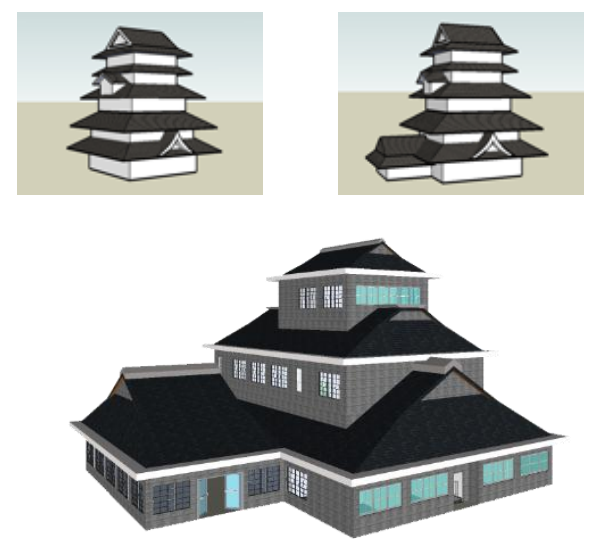

Gambar 12. Transformasi Desain Kantor Pengelola

\section{- Mon (Gerbang Kastil)}

Mon merupakan gerbang kastil yang ditempatkan pada setiap lingkar Bailey. Ada sangat banyak jenis Mon yang biasa dipakai pada kastil Jepang. Dalam sejarah, penempatan Mon dapat dimanfaatkan untuk mengelabui musuh yang hendak menjajah kastil. Mon terbentuk dari kaki-kaki (atau pilar) penyangga dan ditutup oleh atap. [http://www.jcastle.info/resources/view/78-Structures]

Aplikasi Mon pada pusat komunitas terbagi menjadi 3 jenis. Mon untuk masuk kendaraan (baik itu roda 2 hingga truk), Mon untuk pejalan kaki, Mon untuk Bailey lingkar kedua dan ketiga dalam kompleks pusat komunitas. Mon untuk masuk kendaraan dan pejalan kaki memiliki bentuk pilar penyangga yang berbeda dibanding Mon untuk lingkar kedua dan ketiga kompleks pusat komunitas.
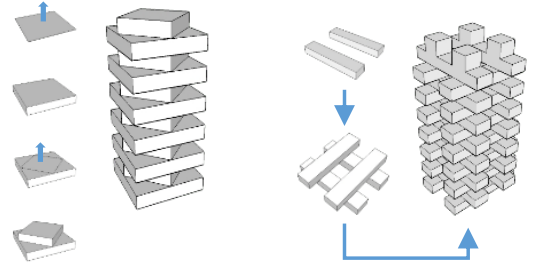

Gambar 13. Transformasi Desain Pilar Penyangga untuk Gerbang Kendaraan dan Pejalan Kaki (Kiri) dan Gerbang Dalam (Kanan)

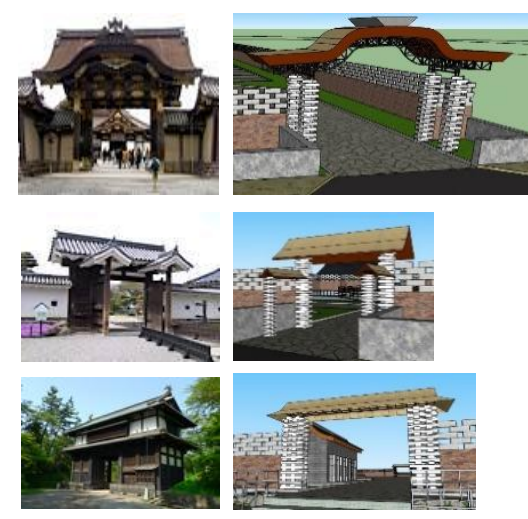

Gambar 14. Transformasi Desain Gerbang

Mon pertama merupakan gerbang untuk masuk kendaraan. Dibentuk dari bentuk Karamon yang terkenal dengan atap melengkungnya. Mon kedua adalah gerbang untuk pejalan kaki. Diebntuk dari bentuk Koraimon yang terkenal dengan 2 atap memanjang pada kedua sisi sampingnya. Mon ketiga adalah gerbang untuk lingkar dalam site. Dibentuk dari Yaguramon yang terkenal sebagai jenis Mon yang paling megah dan mahal.

- Atap Kastil

Atap adalah elemen terakhir yang menjadi keunikan dari kastil-kastil Jepang. Secara umum, ada banyak jenis atap tradisional dari Jepang. Namun untuk penggunaan pada bangunan dalam lingkup kastil, hanya dikenal 2 jenis yang dipakai. Pertama adalah atap Irimoya yang merupakan bentuk atap termegah, termewah, dan hanya biasa digunakan pada bangunan - bangunan penting saja seperti Tenshu. Kedua adalah atap Kirizuma yang merupakan bentuk atap 
yang lebih "merakyat". Penggunaan pada Pusat Komunitas Jepang sesuai kebutuhan bangunan, di mana atap Irimoya hanya digunakan pada bangunan - bangunan dengan ketinggian lebih dari 1 lantai. [http://www.jcastle.info/resources/view/78-Structures]

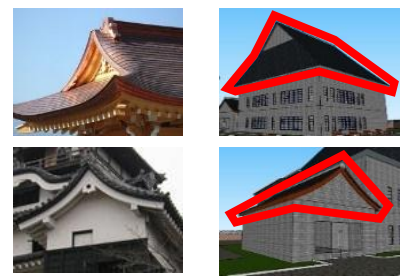

Gambar 15. Transformasi Desain Atap Irimoya

(Atas) dan Atap Kirizuma (Bawah)

Selain itu, pada bagian atap juga dikenal Hafu yang merupakan tenjolan tersendiri pada atap. Biasa digunakn untuk menambah nilai estetis atau menutup bagian kecil pada bangunan. Pada pusat komunitas ada satu bangunan yang memanfaatkan hafu untuk menutup tonjolan hasil bentuk denahnya, yaitu Rumah Teh.
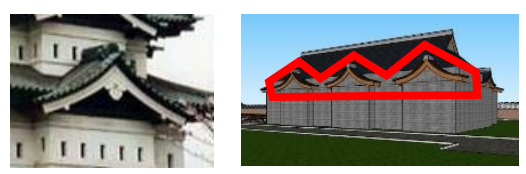

Gambar 16. Penggunaan Hafu pada Bangunan

\section{KESIMPULAN}

Pusat Komunitas ini dirancang sebagai wadah untuk memfasilitasi segala jenis kegiatan dan aktivitas dari komunitas - komunitas Jepang yang berasal dari Solo dan sekitarnya, sarana masyarakat lokal awam dapat memahami lebih dalam mengenai budaya - budaya dan sejarah yang dimiliki oleh negeri Jepang, serta sebagai destinasi wisata sejarah dan budaya baru di sekitar Solo..

Pusat Komunitas dibangun di Kabupaten Karanganyar, Kecamatan Colomadu. Tepatnya di tepi Jalan Laksamana Adi Sucipto, di sebelah Rumah Makan Taman Sari, di atas tanah berukuran $\pm 18.000 \mathrm{~m}^{2}$.

Pusat Komunitas dirancang menggunakan pendekatan Arsitektur Metafora Gabungan dimana penggambaran yang konkrit dan tidak konkrit (abstrak) digabungkan dan diaplikasikan dalam massa bangunan. Perancangan kawasan pusat komunitas ini dilakukan dengan mengacu kepada nama bangunan yang dipilih, yakni Mugen Jou (Kastil Tak Terhingga). Pemilihan nama bangunan dilakukan terkait filosofi dari latar belakang dari fungsi bangunan. Penggambaran konkrit dihadirkan dalam bentuk menumpuk ala lego (mewakili sifat Tak Terhingga) yang dihadirkan ke dalam banyak aspek dalam kawasan pusat komunitas,seperti tembok luar maru, bentuk bangunan-bangunannya, dan beberapa struktur lain di dalam kompleks bangunan. Sedangkan penggambaran abstrak dihadirkan melalui imej kastil secara umum (megah, kokoh, dan massif yang ditunjukan melalui keseluruhan skala infrastruktur terhadap manusia) dan elemen-elemen kastil kuno Jepang ke dalam kawasan (pembahasan dapat dilihat pada sub-judul Analisis Gubahan Massa Bangunan - hal 6).

Pusat Komunitas Jepang dibangun menggunakan bahan dinding yang terbuat dari balok - balok beton dengan warna putih abu. Barisan susunan balok-balok beton juga ikut memperkuat karakter bangunan yang kokoh. Bahan penutup atap menggunakan bahan genting dengan pola urat batu. Bahan ini selain ringan dan kuat, juga ikut memperkuat kesan kastil dari kompleks bangunan karena guratan - guratannya. Bentuk dari jendela-jendela yang dipakai disetarakan dengan bentuk dasar kotak - kotak ala pintu dan jendela tradisional Jepang pada umumnya.

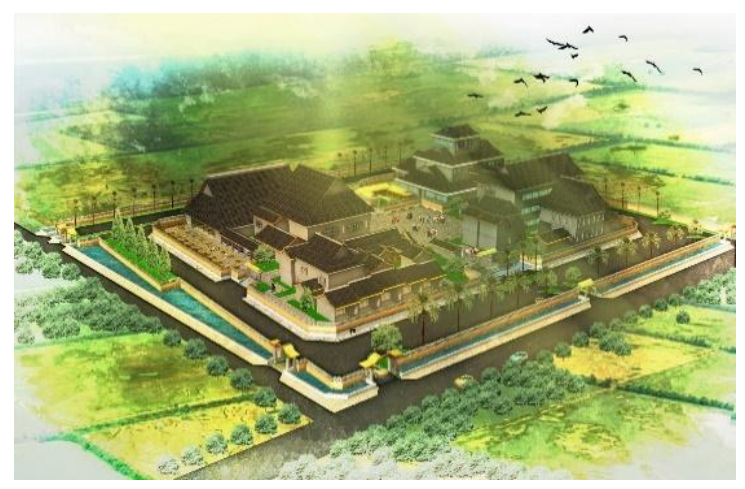

Gambar 17. Perspektif Pusat Komunitas Jepang

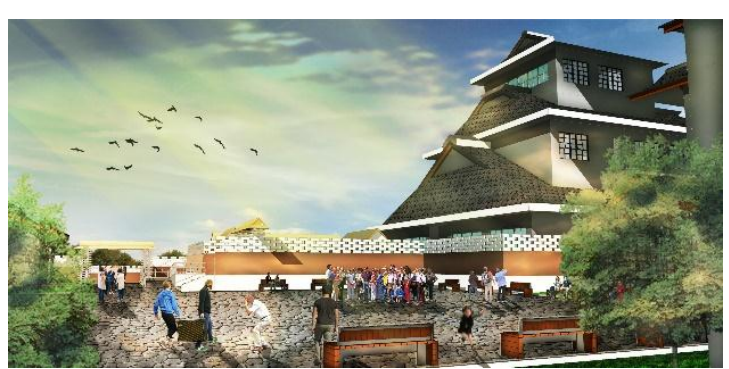

Gambar 18. Suasana Pada Outdoor Plaza 


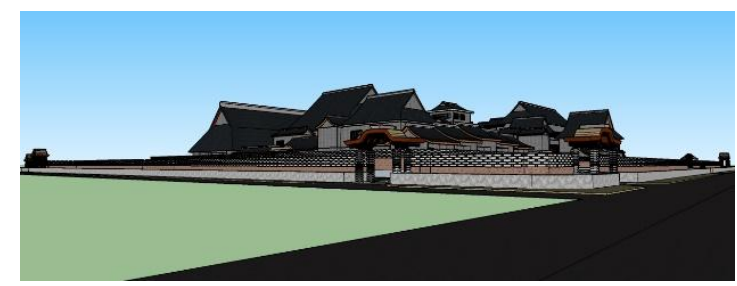

Gambar 19. Perspektif Pengendara pada Pusat Komunitas Jepang

\section{REFERENSI}

Arif, Bahrudin (2009); "Harajuku Style":Kreativitas Dan Nilai-Nilai Hidup Para Pelaku Seni Cosplay Pada Komunitas Harjukja Di Kota Solo, Universitas Muhammadiyah Surakarta, Surakarta

Budaya Populer Jepang Yang Kian Marak, diakses pada Februari 2017, http://www.kompasiana.com/matapanda/ budaya-populer-jepang-yang-kianmarak_57a4a2922123bd9912f4ef0a

Buktikan Sendiri Solo Mirip Kota Nara di Jepang, diakses pada Oktober 2015, http://www.edisicetak.joglosemar.co/beri ta/buktikan-sendiri-solo-mirip-kota-naradi-jepang-75633.html

Japanese Castle Architecture, diakses pada Januari 2017 , http://www.gojapango.com/travel/japane se_castles_architecture.html

Jenck, Charles (1984); The Language of PostModern Architecture - fourth edition, Rizolli, New York

Jepang, diakses pada Januari 2017, http://www.kemlu.go.id/tokyo/id/Pages/J epang.aspx

Jepang: Agen Pop Culture-nya Asia, diakses pada Februari 2017, http://www.kompasiana.com/fitriharyanti /jepang-agen-pop-culture-nyaasia_550e76e1a33311af2dba8106

Structures 建造物, diakses pada Desember 2016, http://www.jcastle.info/resources/view/7 8-Structures
Suhardi, Girinarasoma (2010); Memahami Metafora Arsitektur, Institut Teknologi Bandung, Bandung, Indonesia 